\title{
Neoadjuvant Chemotherapy Increases PD-L1 Expression and CD8+ Tumor-infiltrating Lymphocytes in Esophageal Squamous Cell Carcinoma
}

\author{
EIJI FUKUOKA ${ }^{1}$, KIMIHIRO YAMASHITA ${ }^{1}$, TOMOKO TANAKA $^{1}$, RYUICHIRO SAWADA ${ }^{1}$, \\ YUTAKA SUGITA $^{1}$, AKIRA ARIMOTO ${ }^{1}$, MITSUGU FUJTA ${ }^{2}$, GOSUKE TAKIGUCHI ${ }^{1}$, TAKERU MATSUDA ${ }^{1}$, \\ TARO OSHIKIRI ${ }^{1}$, TETSU NAKAMURA ${ }^{1}$, SATOSHI SUZUKI $^{1}$ and YOSHIHIRO KAKEJI ${ }^{1}$ \\ ${ }^{1}$ Division of Gastrointestinal Surgery, Department of Surgery, \\ Kobe University Graduate School of Medicine, Kobe, Japan; \\ ${ }^{2}$ Department of Microbiology, Kindai University Faculty of Medicine, Osaka, Japan
}

\begin{abstract}
Background/Aim: The aim of this study was to investigate PD-L1 expression and its association with prognosis in esophageal squamous cell carcinoma (ESCC) before and after neoadjuvant chemotherapy (5-fluorouracil and cisplatin, NAC-FP). Patients and Methods: Using a database of 69 ESCC patients, we analyzed PD-L1 expression on tumor cells (TCS) and immune cells (ICs), as well as the density of $\mathrm{CD} 8^{+}$tumor-infiltrating lymphocytes (TILs) in pretreatment biopsy specimens-versus-surgical specimens after resection. We determined the prognostic significance of these factors. Results: The fraction of ESCC containing ICs expressing PD-LI and having a high $C D 8^{+}$ TIL density was significantly increased after neoadjuvant treatment. However, PD-L1 expression on TCs or ICs, and $C D 8^{+}$TIL density, was not significantly associated with patient survival in ESCC patients. Conclusion: NAC-FP induced PD-L1 expression on ICs and CD8 ${ }^{+}$TILs in ESCC patients. This finding suggests that PD-1/PD-L1 blockade could be combined with NAC-FP to treat ESCC patients.
\end{abstract}

Esophageal cancer is the sixth most common cause of cancer-related death, with an estimated 572,000 new cases per year, worldwide (1). It is of two main histological types, esophageal squamous cell carcinoma (ESCC) or esophageal adenocarcinoma. In Asia, incidence rates of squamous cell carcinoma are much higher than adenocarcinoma (2).

Correspondence to: Dr. Kimihiro Yamashita, Division of Gastrointestinal Surgery, Department of Surgery, Kobe University Graduate School of Medicine, 7-5-2 Kusunoki-chou, Chuo-ku, Kobe 650-0017, Japan. Tel: +81 783825925, Fax: +81 783825939, e-mail: kiyama@med.kobe-u.ac.jp

Key Words: Neoadjuvant chemotherapy, esophageal cancer, programmed death-1-ligand.
Neoadjuvant chemotherapy (NAC) or chemoradiotherapy followed by esophagectomy has become the standard treatment worldwide for patients with ESCC. The Japan Clinical Oncology Group 9907study showed that NAC consisting of 5-fluorouracil and cisplatin (FP) significantly extended survival in clinical stage II/III ESCC, but 5-year survival in patients treated with NAC and surgery was still only $54.8 \%$ (3). Therefore, additional treatment strategies are needed to improve the poor prognosis for ESCC patients.

Recently, immune checkpoint inhibitors (ICI) have yielded breakthrough treatments in several different solid cancers (48), including esophageal cancer (9). In order to reliably achieve cures in a greater fraction of patients, perioperative ICI immunotherapy is now being considered. In preclinical models, ICI was shown to be more effective in neoadjuvant, than in the adjuvant form (10). More recently, in the clinical setting, preoperative treatment with a single dose of anti-PD-1 ICI has been shown to be effective in melanoma (11) and non-small-cell lung cancer (NSCLC) (12). In addition, in order to enhance therapeutic efficacy, combination therapies are being enthusiastically tested (13). In ESCC, an in vitro study revealed that FP chemotherapy induced PD-L1 expression (14). Based on these findings, it is hypothesized that a combination of FP and anti- PD-1/PD-L1 ICI is a promising preoperative treatment for ESCC. In this context, in order to study the action of this combination therapy, it is important to analyze the immune tumor microenvironment (iTME) after NAC. Previous studies have shown that the status of the iTME as classified by PD-L1 expression and TIL density, might be predictive of anti-PD-1/PD-L1 ICI efficacy (15). Some studies have documented that PD-L1 expression has prognostic value in ESCC patients undergoing surgery without any neoadjuvant therapy (16-20). However, robust data on PD-L1 expression in ESCC patients treated with NAC are limited $(21,22)$. Therefore, in the present study, we aimed to clarify the effect of NAC on the iTME, utilizing FP 
Table I. Relationships between clinicopathological characteristics and PD-L1 expression.

\begin{tabular}{|c|c|c|c|c|c|c|}
\hline \multirow[t]{2}{*}{ Variable } & \multicolumn{3}{|c|}{ PD-L1 expression (TC) } & \multicolumn{3}{|c|}{ PD-L1 expression (IC) } \\
\hline & $\begin{array}{c}\text { Negative } \\
(\mathrm{n}=38)\end{array}$ & $\begin{array}{c}\text { Positive } \\
(\mathrm{n}=31)\end{array}$ & $p$-Value & $\begin{array}{c}\text { Negative } \\
(\mathrm{n}=13)\end{array}$ & $\begin{array}{c}\text { Positive } \\
(\mathrm{n}=56)\end{array}$ & $p$-Value \\
\hline Age & & & 0.028 & & & 0.700 \\
\hline$<60$ & 11 & 2 & & 3 & 10 & \\
\hline$\geq 60$ years & 27 & 29 & & 10 & 46 & \\
\hline Gender & & & 0.068 & & & 0.674 \\
\hline Male & 36 & 24 & & 11 & 49 & \\
\hline Female & 2 & 7 & & 2 & 7 & \\
\hline Tumor location & & & 0.516 & & & 0.356 \\
\hline Upper & 13 & 7 & & 5 & 15 & \\
\hline Middle & 12 & 10 & & 2 & 20 & \\
\hline Lower & 13 & 14 & & 6 & 21 & \\
\hline Clinical T & & & 0.195 & & & 0.742 \\
\hline$\leq 2$ & 15 & 7 & & 5 & 17 & \\
\hline$\leq 3$ & 23 & 24 & & 8 & 39 & \\
\hline Clinical lymph node metastasis & & & 0.244 & & & 1.000 \\
\hline Negative & 6 & 9 & & 3 & 12 & \\
\hline Positive & 32 & 22 & & 10 & 44 & \\
\hline Clinical stage & & & 0.810 & & & 1.000 \\
\hline$\leq \mathrm{II}$ & 16 & 12 & & 5 & 23 & \\
\hline$\geq \mathrm{III}$ & 22 & 19 & & 8 & 33 & \\
\hline Pathological stage & & & 0.398 & & & 0.157 \\
\hline I & 10 & 6 & & 1 & 15 & \\
\hline II & 8 & 11 & & 6 & 13 & \\
\hline III & 20 & 14 & & 6 & 28 & \\
\hline Grade of response to NAC & & & 1.000 & & & 1.000 \\
\hline$\leq 1 \mathrm{~b}$ & 32 & 27 & & 11 & 48 & \\
\hline 2 & 6 & 4 & & 2 & 8 & \\
\hline
\end{tabular}

(NAC-FP) and measuring PD-L1 expression and CD8 ${ }^{+}$TIL density in ESCC patients. We compared expression in biopsy specimens before NAC-FP and surgical specimens after NAC-FP. In addition, we also aimed to elucidate the impact of PD-L1 expression and CD8 ${ }^{+}$TIL density on the long-term outcomes of ESCC patients treated with NAC-FP followed by surgery with curative intent.

\section{Materials and Methods}

Patients. Of the patients who underwent esophagectomy after chemotherapy at the Kobe University Hospital between 2008 January and 2014 December, 71 met the following criteria and were included in this study: 1) histologically confirmed ESCC by biopsy; 2) R0/R1resection performed; 3) patients completed 2 cycles of FP chemotherapy; 4) paired biopsies and surgical specimens were available. We excluded 2 cases $(2.8 \%)$ because of pathological complete response. Hence, 69 cases were finally enrolled. The Union for International Cancer Control Tumor-Node-Metastasis Classification (7th edition) was used for staging. The histopathological response to NAC was determined according to the criteria of the Japanese Society for Esophageal Diseases. Grades are determined based on the percentage of remaining viable tumor cells within the entire tumor lesion defined as follows: grade 3, no viable residual tumor cells; grade 2 , less than two-thirds; grade 1, twothirds or more; grade 0 , all viable. The FP chemotherapeutic regimen consisted of two cycles of 5 -fluorouracil $\left(800 \mathrm{mg} / \mathrm{m}^{2}\right.$, days $1-5)$ and cisplatin $\left(80 \mathrm{mg} / \mathrm{m}^{2}\right.$, day 1$)$. Surgery was performed about 4-6 weeks after chemotherapy (23). Informed consent was obtained from each patient, and this retrospective study was conducted with the approval of the Institutional Review Board and the Ethics Committee of the Graduate School of Medicine, Kobe University School of Medicine.

Immunohistochemistry (IHC). IHC staining was performed on 4- $\mu$ m slices. Slides were deparaffinized in xylene and rehydrated in a graded series of ethanol dilutions. Antigen retrieval was performed by heating in a pressure oven. Biopsy specimens before NAC and surgical specimens after NAC were immunostained with rabbit monoclonal anti-PD-L1 antibody (dilution 1:100, clone SP142; Spring Bioscience, Pleasanton, CA, USA) and rabbit monoclonal anti-CD8 antibody (dilution 1:100, SP57; Ventana Medical Systems, Tucson, AZ, USA). Human placental tissue was used as a positive control for PD-L1 staining.

Immunohistochemical analysis. PD-L1 expression on tumor cells (TCs) and immune cells (ICs) was evaluated in a semi-quantitative 
$\mathbf{A}$

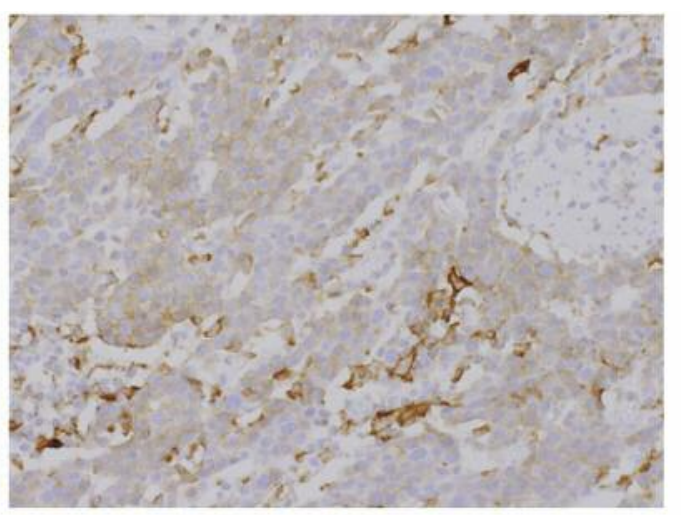

$\mathbf{C}$

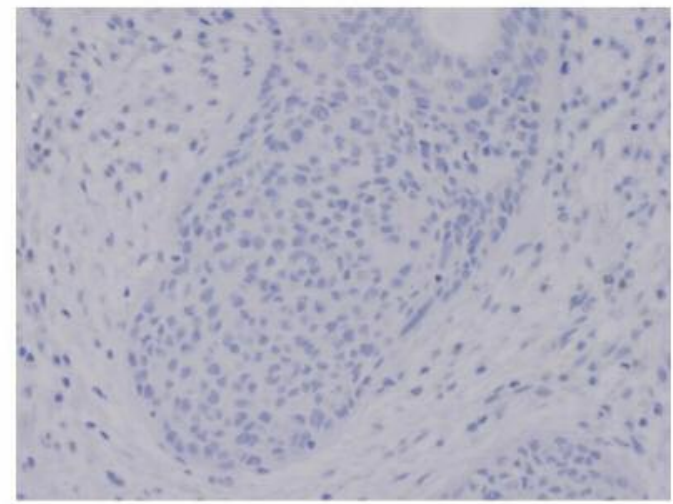

B

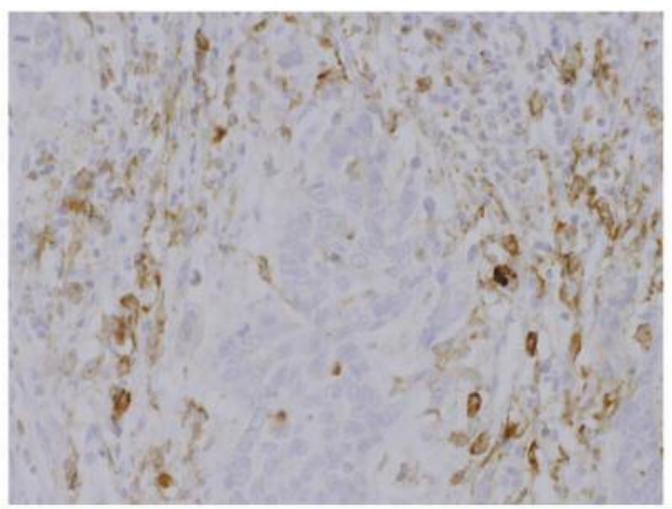

D

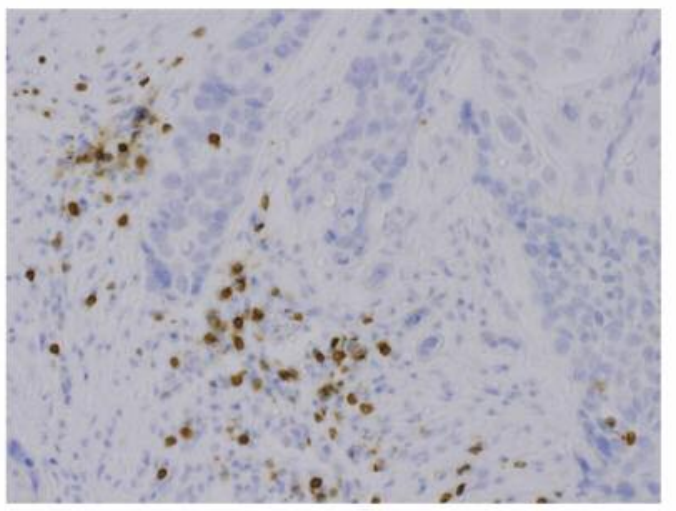

$\mathbf{E}$

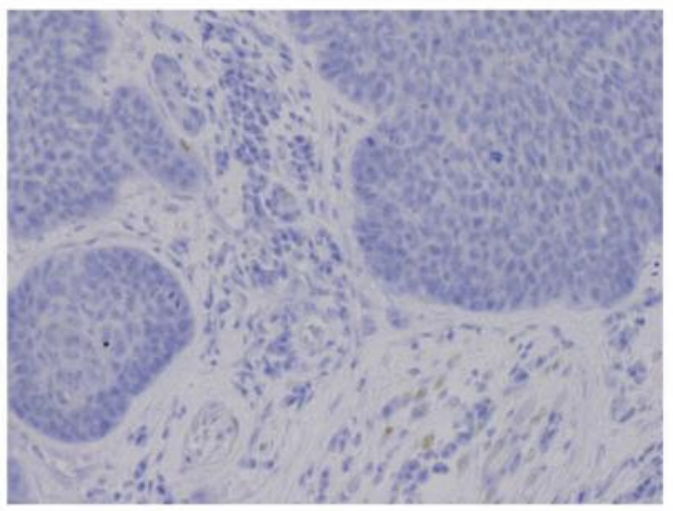

Figure 1. Representative micrographs of sections from esophageal squamous cell carcinoma (ESCC). A. PD-L1 expression on tumor cells (TCs). B. PD-L1 expression on immune cells (ICs). C. PD-L1 expression on neither TCs nor ICs. D. CD8 ${ }^{+}$tumor-infiltrating lymphocytes (TILs) in tumor tissue. E. No CD8+ TILs in tumor tissue. Magnification: 200x.

fashion according to a previously reported scoring system (24). PDL1 expression on TCs was categorized into four groups according to the percentage of PD-L1-positive TCs, namely $\mathrm{TC} 0<1 \%$, $1 \%<\mathrm{TC} 1<5 \%, 5 \%<\mathrm{TC} 2<50 \%$, and $\mathrm{TC} 3 \geq 50 \%$. PD-L 1 expression on IC was categorized into four groups according to the percentage of PD-L1-positive ICs within all ICs in the tumor area as follows: $\mathrm{IC} 0<1 \%, 1 \%<\mathrm{IC} 1<5 \%, 5 \%<\mathrm{IC} 2<10 \%$, and $\mathrm{TC} 3 \geq 10 \%$. CD $8+\mathrm{TIL}$ density was categorized in the same manner as PD-L1 expression on ICs. The immunohistochemical staining was independently evaluated by two of the authors who were blinded to the clinical data. PD-L1 positivity was defined as $\geq 5 \%$ of TCs or ICs (Figure
1). To be scored as positive, the density of $\mathrm{CD} 8^{+}$TILs was defined as $\geq 10 \%$ of ICs.

Statistical analysis. Statistical analyses were conducted using JMP ${ }^{\circledR}$ 11 (SAS Institute Inc., Cary, NC, USA). Pearson's Chi-square test or Fisher's exact test was used to analyze the relationship between immune markers and patient characteristics. McNemar's test was used to analyze changes of PD-L1 expression and CD8 ${ }^{+}$TILs in surgical specimens relative to the values measured in the biopsy specimens. Overall survival (OS) and recurrence-free survival (RFS) were calculated using the Kaplan-Meier method and analyzed using 
the log-rank test. A $p$-value of $<0.05$ was considered to be statistically significant.

\section{Results}

Patient characteristics and immunohistochemistry. Patients at diagnosis ranged in age from 44 to 82 years (median=68 years) and were predominantly male (60 of $69,87.0 \%)$. The location of the tumor was the upper esophagus in 20 patients $(29.0 \%)$, the middle esophagus in $22(31.9 \%)$, and the lower esophagus in $27(39.1 \%)$. The response to NAC was grade 2 in 10 patients $(14.5 \%)$, grade 1 in $51(73.9 \%)$, and grade 0 in the remaining $8(11.6 \%)$. A comparison of the clinicopathological characteristics according to PD-L1 expression on TCs and ICs in surgical specimens is shown in Table I. PD-L1 was expressed on TCs in $44.9 \%$ of patients $(31 / 69)$, and was associated with older age $(\geq 60) \quad(p=0.028)$ (Table I). On the other hand, PD-L1 expression on ICs was observed in $81.2 \%$ of patients (56/69). No relationship was found between PD-L1 expression on ICs and any clinicopathological characteristic.

PD-L1 expression and CD ${ }^{+}$TIL density before and after $N A C$. We compared PD-L1 expression on TCs and ICs, and the density of $\mathrm{CD}^{+}$TILs in biopsy specimens before NAC and surgical specimens after NAC for each ESCC patient according to the scoring system described above (24). The distribution of scores was then examined (Figure 2). Although not statistically significant, the percentage of patients with TCs expressing PD-L1 increased from $34.8 \%$ before NAC to $44.9 \%$ after NAC $(p=0.114)$ (Figure 2A). On the other hand, the percentage of patients with ICs expressing PD-L1 increased from $60.9 \%$ before NAC to $81.2 \%$ after NAC, and this was significant $(p=0.004)$ (Figure $2 \mathrm{~B})$. The percentage of patients with a high density of $\mathrm{CD}^{+}$TILs also increased significantly from $21.7 \%$ before NAC to $66.7 \%$ after NAC $(p<0.001)$ (Figure 2C).

Association of PD-L1 expression and $C D 8^{+}$TIL density with survival. We assessed OS and RFS according to PD-L1 expression on either TCs or ICs, and the density of $\mathrm{CD}^{+}$ TILs but found no significant difference between groups for the entire cohort of patients (Figure 3). Next, we stratified patients into pathological stage I-II- $v s$.-stage III. In stage III, PD-L1 expression on ICs was indeed associated with improved OS and RFS ( $p=0.022$ and $p=0.033$, respectively) (Figure 4A and B), but in patients with stage III disease was not associated with OS or RFS ( $p=0.482$ and $p=0.502$, respectively) (Figure $4 \mathrm{C}, \mathrm{D})$. On the other hand, PD-L1 expression on TCs as well as $\mathrm{CD}^{+}$TIL density was also not associated with survival if the pathological stages were stratified (data not shown).
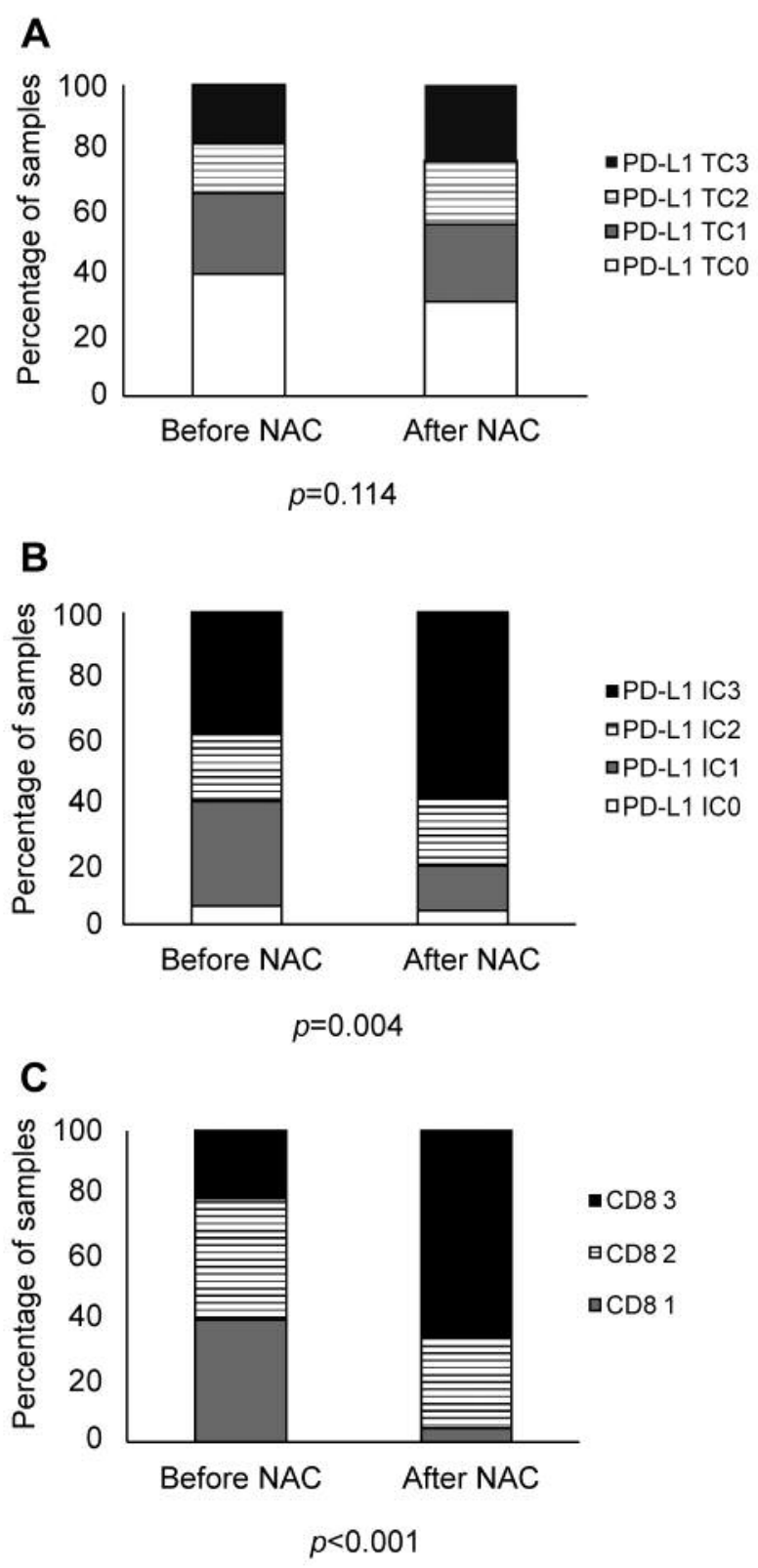

Figure 2. Distribution of $P D-L 1$ expression and $C D 8^{+}$tumor-infiltrating lymphocyte (TIL) density before and after neoadjuvant chemotherapy (NAC). Each sample of designated esophageal squamous cell carcinoma (ESCC) was evaluated by the scoring system described previously (24). A. PD-L1 expression on tumor cells (TCS), B. PD-L1 expression on immune cells (ICs), C. CD8+ TIL density in ESCC.

Univariate and multivariate analyses of OS and RFS. Univariate and multivariate analyses of OS are summarized in Table II. In the former, clinical T, clinical stage, and pathological stage were prognostic factors for OS $(p=0.046$, $p=0.031$, and $p<0.001$, respectively). Pathological stage remained an independent prognostic factor for OS in the 
A

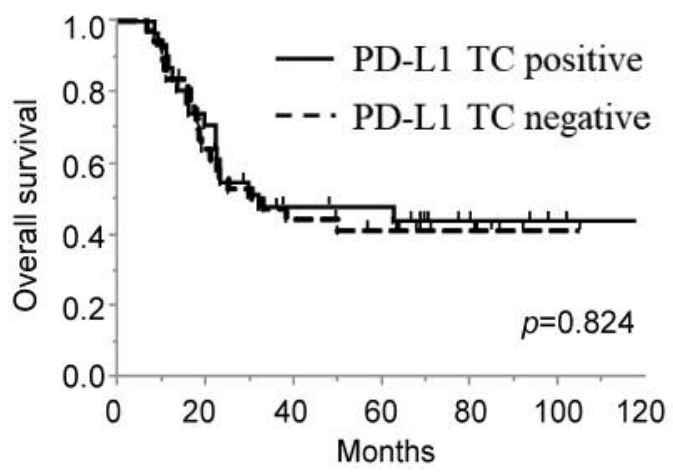

C

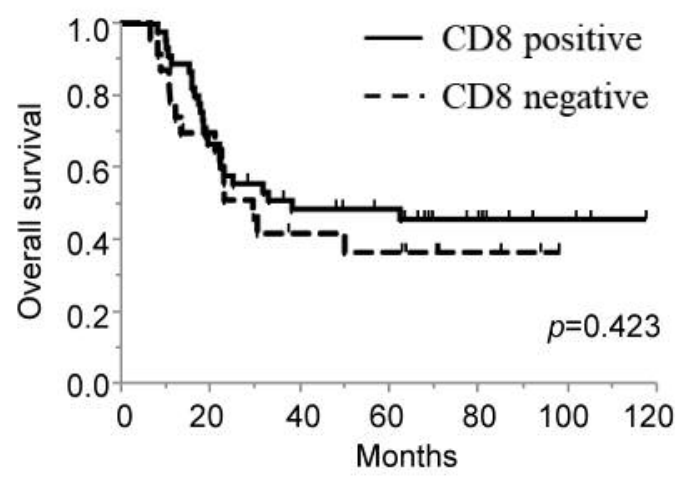

E

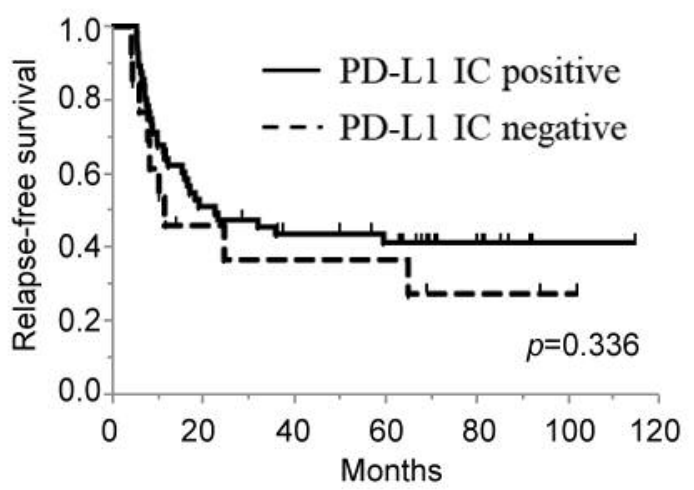

B

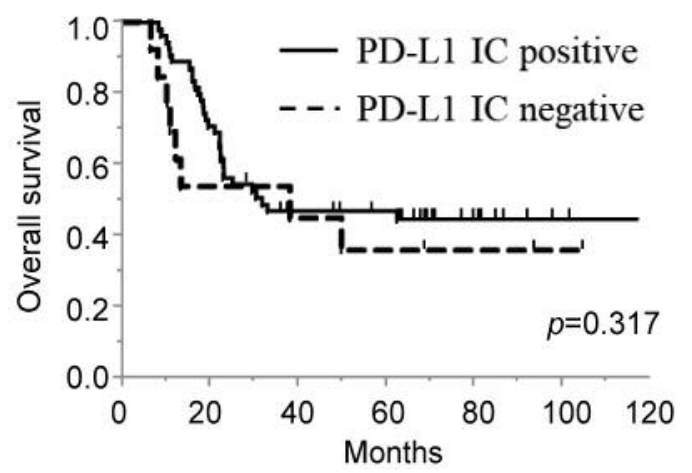

D

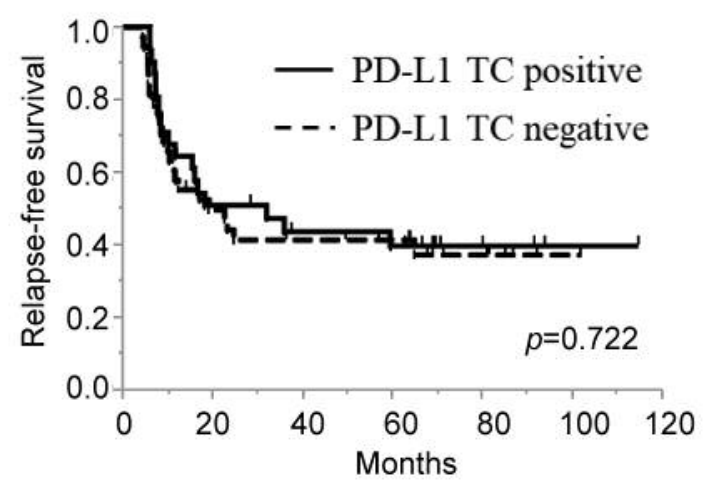

$\mathbf{F}$

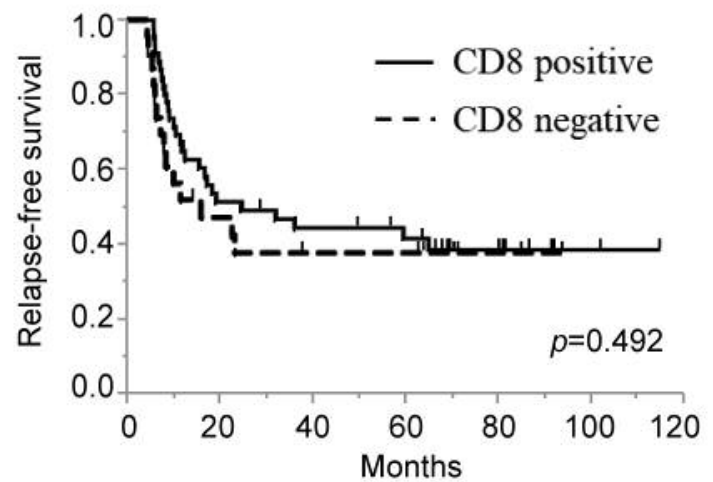

Figure 3. Survival analysis for all 69 esophageal squamous cell carcinoma (ESCC) patients classified according to PD-L1 expression on tumor cells (TCS) or immune cells (ICS), and CD8+ TIL density.

multivariate analysis $(p<0.001)$. Univariate and multivariate analyses of RFS are summarized in Table III. Again, in the univariate analysis, clinical $\mathrm{T}$, clinical stage, and pathological stage were prognostic factors for RFS $(p=0.021, p=0.038$, and $<0.001$, respectively). Also, pathological stage remained the only independent prognostic factor for RFS in the multivariate analysis $(p<0.001)$. Thus, neither PD-L1 expression on TCs or ICs, nor $\mathrm{CD} 8^{+}$TIL density were associated with OS or RFS in the present study.

\section{Discussion}

Here, we showed that PD-L1 expression on ICs, as well as CD8 ${ }^{+}$TIL density, increased significantly following NAC- 
A

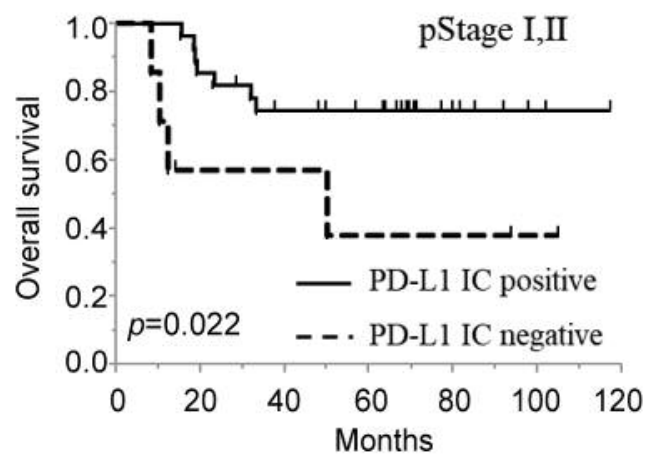

C

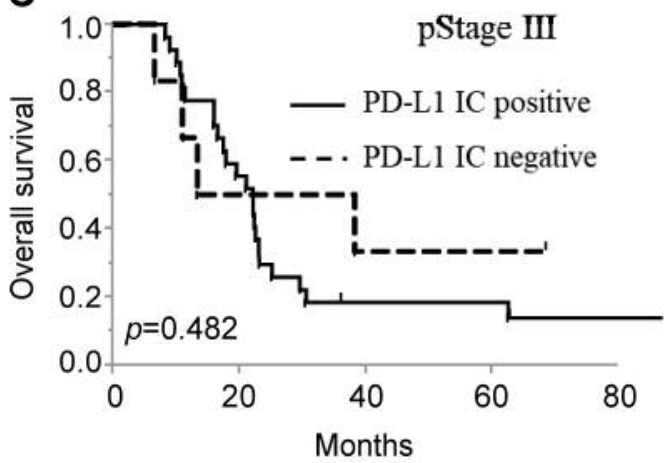

B
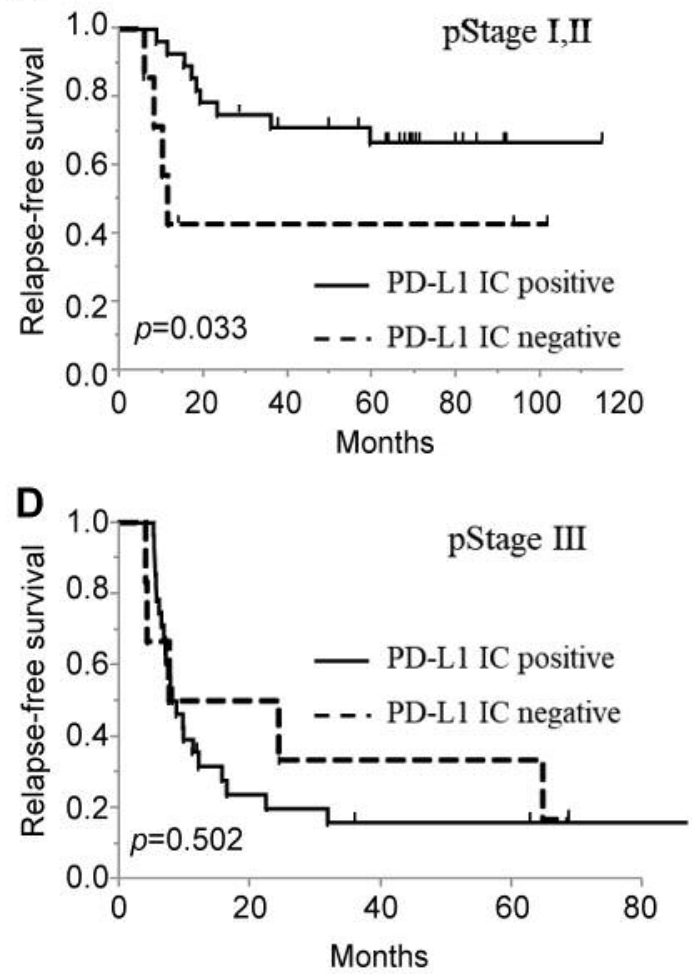

Figure 4. Survival analyses based on pathological stage of esophageal squamous cell carcinoma (ESCC) according to PD-L1 expression on immune cells (ICs). A. Pathological stage I, II patients with PD-L1 expression on ICs had significantly longer overall survival ( $p=0.022)$. B. Pathological stage I, II patients with PD-L1 expression on ICs had significantly longer relapse-free survival ( $p=0.033)$. C and D. In patients with pathological stage III disease, PD-L1 expression on IC was not associated with OS and RFS ( $p=0.482$ and $p=0.502$, respectively).

Table II. Analysis of overall survival.

\begin{tabular}{|c|c|c|c|c|c|}
\hline \multirow[b]{2}{*}{ Variables } & \multirow[t]{2}{*}{ Patients $(n=69)$} & \multicolumn{2}{|c|}{ Univariate Analysis } & \multicolumn{2}{|c|}{ Multivariate analysis } \\
\hline & & HR $(95 \% \mathrm{CI})$ & $p$-Value & HR $(95 \% \mathrm{CI})$ & $p$-Value \\
\hline \multicolumn{6}{|l|}{ Age (year) } \\
\hline$\geq 60 /<60$ & $56 / 13$ & $0.850(0.409-1.992)$ & 0.688 & & \\
\hline \multicolumn{6}{|l|}{ Gender } \\
\hline Male/Female & $60 / 9$ & $2.063(0.742-8.568)$ & 0.183 & & \\
\hline \multicolumn{6}{|l|}{ Clinical T } \\
\hline$\geq 3 / \leq 2$ & $47 / 22$ & $2.058(1.012-4.620)$ & 0.046 & $1.039(0.295-3.260)$ & 0.949 \\
\hline \multicolumn{6}{|l|}{ Clinical N } \\
\hline Positive/negative & $54 / 15$ & $1.491(0.696-3.688)$ & 0.321 & & \\
\hline \multicolumn{6}{|l|}{ Clinical stage } \\
\hline$\geq \mathrm{III} / \leq \mathrm{II}$ & $41 / 28$ & $2.069(1.066-4.257)$ & 0.031 & $0.971(0.347-3.211)$ & 0.959 \\
\hline \multicolumn{6}{|l|}{ Pathological stage } \\
\hline$\geq \mathrm{III} / \leq \mathrm{II}$ & $34 / 35$ & $4.112(2.075-8.726)$ & $<0.001$ & $4.104(1.822-9.803)$ & $<0.001$ \\
\hline \multicolumn{6}{|c|}{ Grade of response to NAC } \\
\hline $2 / \leq 1 b$ & $10 / 59$ & $0.508(0.152-1.277)$ & 0.163 & & \\
\hline \multicolumn{6}{|c|}{ PD-L1 expression (TC) } \\
\hline Positive/negative & $31 / 38$ & $0.930(0.484-1.760)$ & 0.824 & & \\
\hline \multicolumn{6}{|c|}{ PD-L1 expression (IC) } \\
\hline Positive/negative & $56 / 13$ & $0.673(0.323-1.579)$ & 0.340 & & \\
\hline \multicolumn{6}{|l|}{$\mathrm{CD} 8$} \\
\hline Positive/negative & $46 / 23$ & $0.764(0.400-1.517)$ & 0.431 & & \\
\hline
\end{tabular}


Table III. Analysis of recurrence-free survival.

\begin{tabular}{|c|c|c|c|c|c|}
\hline \multirow[b]{2}{*}{ Variables } & \multirow[t]{2}{*}{ Patients $(n=69)$} & \multicolumn{2}{|c|}{ Univariate Analysis } & \multicolumn{2}{|c|}{ Multivariate analysis } \\
\hline & & HR $(95 \% \mathrm{CI})$ & $p$-Value & HR $(95 \% \mathrm{CI})$ & $p$-Value \\
\hline \multicolumn{6}{|l|}{ Age (year) } \\
\hline$\geq 60 /<60$ & $56 / 13$ & $0.844(0.410-1.965)$ & 0.673 & & \\
\hline \multicolumn{6}{|l|}{ Gender } \\
\hline Male/Female & $60 / 9$ & $1.751(0.701-5.854)$ & 0.252 & & \\
\hline \multicolumn{6}{|l|}{ Clinical $\mathrm{T}$} \\
\hline$\geq 3 / \leq 2$ & $47 / 22$ & $2.212(1.120-4.766)$ & 0.021 & $2.061(0.630-6.059)$ & 0.221 \\
\hline \multicolumn{6}{|l|}{ Clinical N } \\
\hline Positive/negative & $54 / 15$ & $1.197(0.595-2.668)$ & 0.629 & & \\
\hline \multicolumn{6}{|l|}{ Clinical stage } \\
\hline$\geq \mathrm{III} / \leq \mathrm{II}$ & $41 / 28$ & $1.955(1.039-3.845)$ & 0.038 & $0.511(0.184-1.643)$ & 0.247 \\
\hline \multicolumn{6}{|l|}{ Pathological stage } \\
\hline$\geq \mathrm{III} / \leq \mathrm{II}$ & $34 / 35$ & $4.264(2.231-8.582)$ & $<0.001$ & $4.396(2.017-10.009)$ & $<0.001$ \\
\hline \multicolumn{6}{|c|}{ Grade of response to NAC } \\
\hline $2 / \leq 1 \mathrm{~b}$ & $10 / 59$ & $0.447(0.134-1.117)$ & 0.090 & $0.443(0.130-1.132)$ & 0.094 \\
\hline \multicolumn{6}{|c|}{ PD-L1 expression (TC) } \\
\hline Positive/negative & $31 / 38$ & $0.894(0.476-1.653)$ & 0.722 & & \\
\hline \multicolumn{6}{|c|}{ PD-L1 expression (IC) } \\
\hline Positive/negative & $56 / 13$ & $0.697(0.347-1.553)$ & 0.356 & & \\
\hline \multicolumn{6}{|l|}{$\mathrm{CD} 8$} \\
\hline Positive/negative & $46 / 23$ & $0.798(0.425-1.566)$ & 0.499 & & \\
\hline
\end{tabular}

FP, but that neither PD-L1 expression on ICs or TCs nor $\mathrm{CD}^{+}$TIL density was associated with survival in ESCC patients after this neoadjuvant chemotherapy (Figures 2 and $3)$. This study is novel, in that we strictly selected pathological samples from curative esophagectomy following completion of two cycles of NAC-FP and were able to compare biopsy specimens before NAC with matched surgical specimens from the same patients after NAC.

Presently, reliable data on PD-L1 expression in ESCC tumors from patients treated with NAC are limited $(21,22)$. In the current study, PD-L1 expression on ICs, as well as $\mathrm{CD}^{+}$TIL density, was found to be significantly increased in NAC-FP-treated ESCC (Figure 2B, C), whereas although PD-L1 expression was also increased on TCs, this failed to reach significance (Figure 2A). To the best of our knowledge, this is the first study to assess PD-L1 expression solely in NAC-FP-pre-treated ESCC patients. PD-L1 upregulation on TCs is consistent with a previous report that patients with tumors expressing PD-L1 were more likely to have received NAC (22). The finding of increased $\mathrm{CD}^{+}$ TILs after NAC is also consistent with a previous report showing that the density of $\mathrm{CD}^{+}$lymphocytes in the stroma was significantly greater in NAC-treated ESCC patients relative to those not receiving NAC (25).

In ESCC patients with no preoperative therapy, most studies have suggested that PD-L1 expression on TCs was associated with poor survival $(16,18,20)$. In contrast, some other reports indicated that PD-L1 expression on TCs was associated with improved survival $(19,26)$. On the other hand, in terms of PD-L1 expression on ICs, a few reports have shown that it was not associated with survival $(18,19)$.

Our study in ESCC patients after NAC-FP showed no positive or negative associations of either PD-L1 expression on ICs or TCs, or $\mathrm{CD}^{+}$TIL density, with survival (Figure 3 ). This is consistent with a previous report that PD-L1 expression on TCs was not significantly associated with survival following preoperative treatment (chemotherapy or chemoradiotherapy) (27). However, PD-L1 expression on ESCC TCs in patients treated with NAC combining cisplatin and 5-FU with adriamycin or docetaxel was reported to be associated with poor survival (22). In addition, PD-L1 expression on ICs was a poor prognostic factor in a study of a ESCC population where most of cases received neoadjuvant treatment (21). Thus, these disparities may be the result of differential treatments and further studies stratifying patients according to each chemotherapy regimen will be required to elucidate the relationship between PD-L1 expression and prognoses of ESCC patients after neoadjuvant treatments.

The present study did show that PD-L1 expression on IC was associated with an improved prognosis in patients with pathological stage I, II disease, but not stage III (Figure 4). The association between PD-L1 expression on ICs and a better clinical outcome has been observed in some types of 
solid cancers $(28,29)$, but the mechanism by which high PDL1 expression on IC contributes to a better clinical outcome remains still unclear. However, our findings may indicate that, in advanced stage ESCC, there is an immune suppression different from that in the early one. Further studies are needed to elucidate the mechanism in the future.

The anti-PD-L1 antibody (clone SP142) used in this study is the reagent used for the complementary diagnostic test for atezolizumab. Previous reports showed that high PD-L1 expression on TCs or ICs (TC3 or IC3) was associated with response to atezolizumab in patients with non-small cell lung cancer (30-32). In that study, PD-L1 TC3 or IC3 in surgical specimens was seen in $66.6 \%$ of patients (46/69). This suggests that ESCC patients pretreated with NAC-FP would be good candidates for responding to atezolizumab treatment. Additionally, a previous report showed that the presence of $\mathrm{CD}^{+}$TILs before anti-PD-1 ICI predicts the response in melanoma (33). These findings suggest that pre-treatment of ESCC patients with NAC-FP would increase their responsiveness to anti-PD-1/PD-L1 ICI. Indeed, a phase I clinical trial of atezolizumab in combination with fluorouracil and oxaliplatin for esophageal cancer is ongoing and looks promising. Further studies are needed to develop more efficient neoadjuvant strategies in combination with antiPD-1/PD-L1 ICI using biomarkers to predict responses.

A limitation of this study is the potential discordance between biopsy specimens and surgical specimens regarding the estimation of PD-L1 expression. Ilie et al. have reported that results from biopsy specimens underestimated PD-L1 expression as assessed in surgical specimens from patients with advanced non-small cell lung cancer (34).

In conclusion, NAC-FP increased PD-L1 expression and $\mathrm{CD}^{+}$TIL density in ESSC patients and PD-L1 expression on TCs or ICs, and CD8 ${ }^{+}$TIL density, was not significantly associated with patient survival in ESCC patients. Further studies are needed to develop more effective neoadjuvant strategies in combination with anti-PD-1/PD- L1 ICI to improve the clinical outcome of ESCC.

\section{Conflicts of Interest}

The Authors declared that they have no conflict of interest in regard to this study.

\section{Authors' Contributions}

Conception and design: Yoshihiro Kakeji, Kimihiro Yamashita, Mitsugu Fujita, Eiji Fukuoka; Acquisition of data: Eiji Fukuoka, Tomoko Tanaka, Ryuichiro Sawada, Yutaka Sugita, Akira Arimoto, Gosuke Takiguchi, Takeru Matsuda, Taro Oshikiri, Tetsu Nakamura, Satoshi Suzuki;Analysis and interpretation of data: Eiji Fukuoka; Writing, review, and revision of manuscript: Eiji Fukuoka, Kimihiro Yamashita, Yoshihiro Kakeji.

\section{Acknowledgements}

This work was supported by a Grant-in-Aid for Scientific Research (B) $16 \mathrm{H} 05415$ from the Ministry of Education, Culture, Sports, Science and Technology of Japan, and grants from the Uehara Memorial Foundation.

\section{References}

1 Ferlay J, Colombet M, Soerjomataram I, Mathers C, Parkin DM, Piñeros M, Znaor A and Bray F: Estimating the global cancer incidence and mortality in 2018: GLOBOCAN sources and methods. Int J Cancer 44(8): 1941-1953, 2019. PMID: 30350 310. DOI: $10.1002 / \mathrm{ijc} .31937$

2 Shibata A, Matsuda T, Ajiki W and Sobue T: Trend in incidence of adenocarcinoma of the esophagus in Japan, 1993-2001. Jpn J Clin Oncol 38: 464-468, 2008. PMID: 18664481. DOI: 10.1093/ jjco/hyn064

3 Ando N, Kato H, Igaki H, Shinoda M, Ozawa S, Shimizu H, Nakamura T, Yabusaki H, Aoyama N, Kurita A, Ikeda K, Kanda T, Tsujinaka T, Nakamura $\mathrm{K}$ and Fukuda $\mathrm{H}$ : A randomized trial comparing postoperative adjuvant chemotherapy with cisplatin and 5-fluorouracil versus preoperative chemotherapy for localized advanced squamous cell carcinoma of the thoracic esophagus (JCOG9907). Ann Surg Oncol 19: 68-74, 2012. PMIDD21879261. DOI: 10.1245/s10434-011-2049-9

4 Horn L, Spigel DR, Vokes EE, Holgado E, Ready N, Steins M, Poddubskaya E, Borghaei H, Felip E, Paz-Ares L, Pluzanski A, Reckamp KL, Burgio MA, Kohlhäeufl M, Waterhouse D, Barlesi F, Antonia S, Arrieta O, Fayette J, Crinò L, Rizvi N, Reck M, Hellmann MD, Geese WJ, Li A, Blackwood-Chirchir A, Healey D, Brahmer J and Eberhardt WEE: Nivolumab versus docetaxel in previously treated patients with advanced non-small-cell lung cancer: Two-year outcomes from two randomized, open-label, phase III Trials (CheckMate 017 and CheckMate 057). J Clin Oncol 35: 3924-3933, 2017. PMID: 29023213. DOI: 10.1200/ JCO.2017.74.3062

5 Wolchok JD, Chiarion-Sileni V, Gonzalez R, Rutkowski P, Grob J-J, Cowey CL, Lao CD, Wagstaff J, Schadendorf D, Ferrucci PF, Smylie M, Dummer R, Hill A, Hogg D, Haanen J, Carlino MS, Bechter O, Maio M, Marquez-Rodas I, Guidoboni M, McArthur G, Lebbé C, Ascierto PA, Long GV, Cebon J, Sosman J, Postow MA, Callahan MK, Walker D, Rollin L, Bhore R, Hodi FS and Larkin J: Overall survival with combined nivolumab and ipilimumab in advanced melanoma. $\mathrm{N}$ Engl $\mathrm{J}$ Med 377: 1345-1356, 2017. PMID: 28889792. DOI: 10.1056/ NEJMoa1709684

6 Kang YK, Boku N, Satoh T, Ryu MH, Chao Y, Kato K, Chung HC, Chen JS, Muro K, Kang WK, Yeh KH, Yoshikawa T, Oh SC, Bai LY, Tamura T, Lee KW, Hamamoto Y, Kim JG, Chin K, Oh DY, Minashi K, Cho JY, Tsuda M and Chen LT: Nivolumab in patients with advanced gastric or gastro-oesophageal junction cancer refractory to, or intolerant of, at least two previous chemotherapy regimens (ONO-4538-12, ATTRACTION-2): a randomised, double-blind, placebo-controlled, phase 3 trial. Lancet 390: 2461-2471, 2017. PMID: 28993052. DOI: 10.1016/S0140-6736(17)31827-5

7 Hammers HJ, Plimack ER, Infante JR, Rini BI, McDermott DF, Lewis LD, Voss MH, Sharma P, Pal SK, Abdul Razak AR, Kollmannsberger C, Heng DYC, Spratlin J, Brent McHenry M 
and Amin A: Safety and efficacy of nivolumab in combination with ipilimumab in metastatic renal cell carcinoma: The checkmate 016 study. J Clin Oncol 35: 3851-3858, 2017. PMID: 28678668. DOI: $10.1200 / J C O .2016 .72 .1985$

8 Gadducci A and Guerrieri ME: Immune checkpoint inhibitors in gynecological cancers: update of literature and perspectives of clinical research. Anticancer Res 37: 5955-5965, 2017. PMID: 29061774. DOI: 10.21873/anticanres.12042

9 Doi T, Piha-Paul SA, Jalal SI, Saraf S, Lunceford J, Koshiji M and Bennouna J: Safety and antitumor activity of the antiprogrammed death- 1 antibody pembrolizumab in patients with advanced esophageal carcinoma. J Clin Oncol 36: 61-67, 2018. PMID: 29116900. DOI: 10.1200/JCO.2017.74.9846

10 Liu J, Blake SJ, Yong MCR, Harjunpää H, Ngiow SF, Takeda K, Young A, O'Donnell JS, Allen S, Smyth MJ and Teng MWL: Improved efficacy of neoadjuvant compared to adjuvant immunotherapy to eradicate metastatic disease. Cancer Discov 6: 1382-1399, 2016. PMID: 27663893. DOI: 10.1158/21598290.CD-16-0577

11 Eggermont A, Blank C, Mandala M, Long G, Atkinson V, Dalle S, Haydon A, Lichinirser M, Khattak A, Carlino M, Sandhu S, Larkin J, Puig S, Ascierto P, Rutkowski P, Schadendorf D, Koomstra R, Hernandez L, Maio M, Eertwegh A, Gorb J-J, Gutzmer R, Jamal R, Lorigan P, Ibrahim N, Marreaud S, Akkooi A, Suciu $S$ and Robert C: Adjuvant pembrolizumab versus placebo in resected stage III melanoma. N Engl J Med 378: 1789-1801, 2018. PMID: 29658430. DOI: $10.1056 /$ nejmoa 1802357

12 Forde PM, Chaft JE, Smith KN, Anagnostou V, Cottrell TR, Hellmann MD, Zahurak M, Yang SC, Jones DR, Broderick S, Battafarano RJ, Velez MJ, Rekhtman N, Olah Z, Naidoo J, Marrone KA, Verde F, Guo H, Zhang J, Caushi JX, Chan HY, Sidhom J-W, Scharpf RB, White J, Gabrielson E, Wang H, Rosner GL, Rusch V, Wolchok JD, Merghoub T, Taube JM, Velculescu VE, Topalian SL, Brahmer JR and Pardoll DM: Neoadjuvant PD-1 blockade in resectable lung cancer TL - 378. N Engl J Med 378: 1976-1986, 2018. PMID: 29658848. DOI: 10.1056/nejmoa1716078

13 Tang J, Shalabi A and Hubbard-Lucey VM: Comprehensive analysis of the clinical immuno-oncology landscape. Ann Oncol 29: 84-91, 2018. PMID: 25581449. DOI: 10.1093/annonc/ $\operatorname{mdx} 755$

14 Ng HY, Li J, Tao L, Mun J, Ko Y and Yu VZ: Chemotherapeutic treatments increase PD-L1 expression in esophageal squamous cell carcinoma through EGFR/ERK activation. Transl Oncol 11: 1323-1333, 2018. PMID: 30172884. DOI: 10.1016/j.tranon. 2018.08.005

15 Teng MWL, Ngiow SF, Ribas A and Smyth MJ: Classifying cancers based on Tcell infiltration and PD-L1. Cancer Res 75: 2139-2145, 2016. PMID: 25977340. DOI: 10.1158/00085472.CAN-15-0255.

16 Tsutsumi S, Saeki H, Yuichiro N, Ito S, Oki E, Morita M, Oda Y, Okano S and Maehara Y: Programmed death-ligand 1 expression at tumor invasive front is associated with epithelialmesenchymal transition and poor prognosis in esophageal squamous cell carcinoma. Cancer Sci 108: 1119-1127, 2017. PMID: 28294486. DOI: 10.1111/cas.13237

17 Zhang W, Pang Q, Zhang X, Yan C, Wang Q, Yang J, Yu S, Liu X, Pan Y, Yuan Z, Wang P and Xiao Z: Programmed deathligand 1 is prognostic factor in esophageal squamous cell carcinoma and is associated with epidermal growth factor receptor. Cancer Sci 108: 590-597, 2017. PMID: 28192623. DOI: $10.1111 /$ cas.13197

18 Rong L, Liu Y, Hui Z, Zhao Z, Zhang Y, Wang B, Yuan Y, Li W, Guo L, Ying J, Song Y, Wang L, Zhou Z, Xue L and Lu N: PD$\mathrm{L} 1$ expression and its clinicopathological correlation in advanced esophageal squamous cell carcinoma in a Chinese population. Diagn Pathol 14: 1-10, 2019. PMID: 30684971. DOI: 10.1186/s13000-019-0778-4

19 Jiang D, Song Q, Wang H, Huang J, Wang H, Hou J, Li X, Xu Y, Sujie A, Zeng H, Tan L and Hou Y: Independent prognostic role of PD-L1 expression in patients with esophageal squamous cell carcinoma. Oncotarget 8: 8315-8329, 2016. PMID: 28039448. DOI: 10.18632 /oncotarget.14174

20 Leng C, Li Y, Liu X, Hua X, Cui Y, Ma J, Wang Z, Wang W, Zhang J, Zhu J, Wang Q, Yu Y, Qin J, Sun H, Li H and Zheng Y: Relationship between expression of PD-L1 and PD-L2 on esophageal squamous cell carcinoma and the antitumor effects of $\mathrm{CD}^{+}{ }^{+} \mathrm{T}$ cells. Oncol Rep 35: 699-708, 2015. PMID: 26718132. DOI: $10.3892 /$ or.2015.4435

21 Momose K, Yamasaki M, Tanaka K, Miyazaki Y, Makino T, Takahashi T, Kurokawa Y, Nakajima K, Takiguchi S, Mori M and Doki Y: MLH1 expression predicts the response to preoperative therapy and is associated with PD-L1 expression in esophageal cancer. Oncol Lett 14: 958-964, 2017. PMID: 28693258. DOI: 10.3892/ol.2017.6215

22 Tanaka K, Miyata H, Sugimura K, Kanemura T, Hamadauematsu M, Mizote Y, Yamasaki M, Wada H, Nakajima K, Takiguchi S, Mori M and Doki Y: Negative influence of programmed death-1-ligands on the survival of esophageal cancer patients treated with chemotherapy. Cancer Sci 107: 726733, 2016. PMID: 27015293. DOI: 10.1111/cas.12938

23 Ando N, Kato H, Igaki H, Shinoda M, Ozawa S, Shimizu H, Nakamura T, Yabusaki H, Aoyama N, Kurita A, Ikeda K, Kanda T, Tsujinaka T, Nakamura $\mathrm{K}$ and Fukuda $\mathrm{H}$ : A randomized trial comparing postoperative adjuvant chemotherapy with cisplatin and 5-fluorouracil versus preoperative chemotherapy for localized advanced squamous cell carcinoma of the thoracic esophagus (JCOG9907). Ann Surg Oncol 19: 68-74, 2012. DOI: 10.1245/s10434-011-2049-9

24 Herbst RS, Soria JC, Kowanetz M, Fine GD, Hamid O, Gordon MS, Sosman JA, McDermott DF, Powderly JD, Gettinger SN, Kohrt HEK, Horn L, Lawrence DP, Rost S, Leabman M, Xiao Y, Mokatrin A, Koeppen H, Hegde PS, Mellman I, Chen DS and Hodi FS: Predictive correlates of response to the anti-PD-L1 antibody MPDL3280A in cancer patients. Nature 515: 563-567, 2014. PMID: 25428504. DOI: 10.1038/nature14011

25 Tsuchikawa T, MD MM, Yamamura Y, Shichinohe T, Hirano S and Kondo S: The immunological impact of neoadjuvant chemotherapy on the tumor microenvironment of esophageal squamous cell carcinoma. Ann Surg Oncol 19: 1713-1719, 2012. PMID: 21822560. DOI: 10.1245/s10434-011-1906-x

26 Wakita A, Motoyama S, Nanjo H, Sato Y, Yoshino K, Sasaki T, Kawakita Y, Liu J, Imai K, Saito H and Minamiya Y: PD-L1 expression is a prognostic factor in patients with thoracic esophageal cancer treated without adjuvant chemotherapy. Anticancer Res 37: 1433-1441, 2017. PMID: 28314315. DOI: 10.21873/anticanres.11467

27 Yagi T, Baba Y, Ishimoto T, Iwatsuki M, Miyamoto Y, Yoshida $\mathrm{N}$, Watanabe $\mathrm{M}$ and Baba H: PD-L1 expression, tumor- 
infiltrating lymphocytes, and clinical outcome in patients with surgically resected esophageal cancer. Ann Surg 269: 471-478, 2019. PMID: 29206673. DOI: 10.1097/SLA.0000000000002616

28 Kim IY, You SH and Kim YW: Neutrophil-lymphocyte ratio predicts pathologic tumor response and survival after preoperative chemoradiation for rectal cancer. BMC Surg 14: 17, 2014. PMID: 25406793. DOI: 10.1186/1471-2482-14-94

29 Kim HR, Ha SJ, Hong MH, Heo SJ, Koh YW, Choi EC, Kim EK, Pyo KH, Jung I, Seo D, Choi J, Cho BC and Yoon SO: PD-L1 expression on immune cells, but not on tumor cells, is a favorable prognostic factor for head and neck cancer patients. Sci Rep 6: 36956, 2016. PMID: 27841362. DOI: 10.1038/ srep36956

30 Kowanetz M, Zou W, Gettinger SN, Koeppen H, Kockx M, Schmid P, Kadel EE, Wistuba I, Chaft J, Rizvi NA, Spigel DR, Spira A, Hirsch FR, Cohen V, Smith D, Boyd Z, Miley N, Flynn S, Leveque V, Shames DS, Ballinger M, Mocci S, Shankar G, Funke R, Hampton G, Sandler A, Amler L, Mellman I, Chen DS and Hegde PS: Differential regulation of PD-L1 expression by immune and tumor cells in NSCLC and the response to treatment with atezolizumab (anti-PD-L1). Proc Natl Acad Sci 115: E10119-E10126, 2018. PMID: 30297397. DOI: 10.1073/ pnas.1802166115

31 Horn L, Gettinger SN, Gordon MS, Herbst RS, Gandhi L, Felip E, Sequist L V., Spigel DR, Antonia SJ, Balmanoukian A, Cassier PA, Liu B, Kowanetz M, O'Hear C, Fassò M, Grossman W, Sandler A and Soria JC: Safety and clinical activity of atezolizumab monotherapy in metastatic non-small-cell lung cancer: final results from a phase I study. Eur J Cancer 101: 201209, 2018. PMID: 30077125. DOI: 10.1016/j.ejca.2018.06.031
32 Fehrenbacher L, Spira A, Ballinger M, Kowanetz M, Vansteenkiste J, Mazieres J, Park K, Smith D, Artal-Cortes A, Lewanski C, Braiteh F, Waterkamp D, He P, Zou W, Chen DS, Yi J, Sandler A and Rittmeyer A: Atezolizumab versus docetaxel for patients with previously treated non-small-cell lung cancer (POPLAR): A multicentre, open-label, phase 2 randomised controlled trial. Lancet 387: 1837-1846, 2016. PMID: 26970723. DOI: $10.1016 / \mathrm{S} 0140-6736(16) 00587-0$

33 Tumeh PC, Harview CL, Yearley JH, Shintaku IP, Taylor EJM, Robert L, Chmielowski B, Spasic M, Henry G, Ciobanu V, West AN, Carmona M, Kivork C, Seja E, Cherry G, Gutierrez AJ, Grogan TR, Mateus C, Tomasic G, Glaspy JA, Emerson RO, Robins H, Pierce RH, Elashoff DA, Robert C and Ribas A: PD1 blockade induces responses by inhibiting adaptive immune resistance. Nature 515: 568-571, 2014. PMID: 25428505. DOI: 10.1038 /nature 13954

34 Ilie M, Bence C, Butori C, Lassalle S, Bouhlel L, Fazzalari L, Zahaf K, Washetine K, Mouroux J, Poudenx M, Otto J, Sabourin JC, Marquette $\mathrm{CH}$, Hofman V and Hofman P: Comparative study of the PD-L1 status between surgically resected specimens and matched biopsies of issue for anti-PD-L1 therapeutic strategies. Ann Oncol 27: 147-153, 2016. PMID: 26483045. DOI: $10.1093 /$ annonc/mdv489 